\title{
Early exposure to environment sounds and the development of cortical auditory evoked potentials of preterm infants during the first 3 months of life
}

Hannalice Gottschalck Cavalcanti ${ }^{1}$, Aryelly Dayane da Silva Nunes ${ }^{2}$, Brenda Karla Silva da Cunha ${ }^{2}$, Kátia de Freitas Alvarenga ${ }^{3}$, Sheila Andreoli Balen ${ }^{4}$ and Antonio Pereira Jr. ${ }^{5^{*}}$ (D)

\begin{abstract}
Objective: Preterm infants are exposed earlier than their term counterparts to unattenuated sounds from the external environment during the sensitive period of the organization of the auditory cortical circuitry. In the current study, we investigate the effect of preterm birth on the course of development of auditory cortical areas by evaluating how gestational age (GA) correlates with the latency of the P1 component of the cortical auditory evoked potential (CAEP) of two experimental groups measured at 1 or 3 months of age.

Results: Our sample consisted of 23 infants delivered at GA ranging from 31.28 to 41.42 weeks and separated into two groups evaluated transversally at 1 or 3 months of corrected age (CA). In the group evaluated at 1-month CA, the latency of the component P1 was similar in both terms and infants classified as late-preterm (GA>32 weeks). However, in the group evaluated at 3 months CA, P1 latency was significantly smaller in preterms. These preliminary results suggest an acceleration of the development of auditory cortical pathways in preterms, probably due to their early exposure to socially relevant auditory stimuli from the external environment.
\end{abstract}

Keywords: Preterm, Newborn, Brain development, Auditory, Cortex

\section{Introduction}

The remarkable adaptability of the human brain results from the interplay of both evolutionary and developmental mechanisms. Genetically determined developmental programs set up the stage upon which cortical circuits are sculpted by experience and learning, particularly during the sensitive periods of synaptic plasticity [1-3]. The primary auditory cortex is structurally mature as early as 28 weeks of gestation [4] and already responds

*Correspondence: apereira@ufpa.br

${ }^{5}$ Department of Electrical and Biomedical Engineering, Institute

of Technology, Federal University of Pará, Rua Augusto Correa, S/N, Belém,

PA 66075-110, Brazil

Full list of author information is available at the end of the article electrically to sounds in the low-frequency range associated with speech $[5,6]$. This could explain why newborns can discriminate their mothers' voice immediately after birth $[7,8]$.

While our understanding of the prenatal emergence of the cortical organization has traditionally depended on animal-based research, due to ethical concerns, preterm birth offers a unique opportunity to investigate this issue in human subjects as well. The extra period of sensory stimulation afforded by preterms allows the earlier maturation of binocular vision and thalamocortical connectivity to the primary somatosensory cortex $[9,10]$.

Preterm birth is characterized by delivery before 37 weeks of GA $[11,12]$ and the following sub-categories of preterms are proposed, based on GA: extremely 
preterm ( $<28$ weeks), very preterm $(28$ to $<32$ weeks), and moderate to late preterm (32 to $<37$ weeks) [13]. Most preterm births $(>70 \%)$ are considered late-preterm (34 to $<37$ weeks) [14] and they account for about 85 of all births [15]. Since late-preterm births occur during the period when cortical volume increases by $50 \%$ (3440 weeks), there is a pressing need to understand the possible effects of premature exposure to the extrauterine environment in this population $[15,16]$.

The cortical auditory evoked potential (CAEP) is characterized by waveforms with positive and negative deflections occurring between 0 and $300 \mathrm{~ms}$ after sound onset in adults. The earliest components are called P1 and N1 and are already present in newborns $[17,18]$. The latency of the P1 component shows a steady decrease until it stabilizes in adulthood [19-22] and has been proposed as a biomarker for the maturation of cortical sensory pathways $[17,21,23]$. In the present study, we evaluate the development of the cortical auditory pathway of late preterms in the first 3 months of life.

\section{Main text \\ Methods \\ Subjects}

This study was approved by the Research Ethics Committee of the Federal University of Rio Grande do Norte (\#340.110) and written informed parental consent was obtained on behalf of all participants. The participants were 23 newborns (GA: 31.28-41.42 weeks) recruited at the Maternity School of the Federal University of Rio Grande do Norte according to the following inclusion criteria: no signs of hearing problems during routine maternity screening, normal Auditory Brainstem Responses (ABR) with a click and normal threshold for ABR tone burst at $500 \mathrm{~Hz}, 1000 \mathrm{~Hz}$ and $4000 \mathrm{~Hz}$ in both ears, normal Distortion Product Otoacoustic Emissions (DPOAE) and tympanometry result with curve type $A$ in both ears. Table 1 shows the demographic characteristics and birth outcomes of mothers and infants.

\section{Procedure and stimuli}

The design of the study was cross-sectional and the subjects were evaluated at 1 or 3 months after birth and were divided into two groups according to their GA: preterm or term. For the CAEP recordings, subjects were accommodated either on a car seat or in the caregivers' lap within a sound-attenuated room. All tests were performed while infants were in stage 4 of the Neonatal Behavioral Assessment Scale [24]: alert, awake state.

We used ER-3A insert phones (Etymotic Research, Inc.) for sound delivery to the right ear and the CAEP recordings were performed with a Smart EP USB Jr system with two channels (Intelligent Hearing Systems,
Inc.). The CAEP was recorded on channel A, while channel $B$ was used to register eye movements for off-line artifact removal and to determine the rejection level for each session. Disposable surface electrodes were used for the recording procedures. The CAEP was recorded at the midline $(\mathrm{Cz})$ and referenced to the right mastoid. The ground electrode was placed at the left mastoid. All electrode impedances were less than $3 \mathrm{k} \Omega$. A minimum of 150 stimuli was presented and the resulting signal, within an analysis window of $-100 \mathrm{~ms}$ pre-stimulus and $500 \mathrm{~ms}$ post-stimulus, was averaged at both $70 \mathrm{~dB} N A$ and $0 \mathrm{~dB}$ NA after band-pass filtering from 1 to $30 \mathrm{~Hz}$. The gain in both channels was 100,000 . The rate of the stimulus was $1.9 \mathrm{~s}$.

Auditory responses were recorded in response to a/da/ speech stimulus with an intensity of $70 \mathrm{~dB} \mathrm{HL}$ and with an interstimulus interval of $526.00 \mathrm{~ms}$. The/da/sound was recorded with the software praat (https://www.praat.org) using a unidirectional microphone in an acoustically isolated room [25]. The latency of component P1 was determined as the first positive peak after $50 \mathrm{~ms}$, following a negative decline. The latency of the P1 component was confirmed independently by two experienced judges.

\section{Statistical analysis}

Only 2-sided tests and nonparametric statistical tests were used due to the non-normal distribution of variables and/or sample size. Sample characteristics were compared using Pearson's Chi square test or Fisher's exact test. Results are expressed as mean \pm standard deviation. Samples' comparison at 1- and 3-months CA were performed with a two-tailed Mann-Whitney rank sum $\mathrm{U}$ test. The relationship between GA and $\mathrm{p} 1$ latency was assessed with the Spearman correlation $(r)$. The significance level was set at 0.05 .

\section{Results}

P1 latency is not correlated with GA at both $1\left(r_{s}=0.44\right.$, $p=0.183)$ and $3\left(r_{s}=0.49, p=0.109\right)$ months CA. We computed linear regression lines to fit the P1 latency data (Fig. 1a) and though the slopes of regression lines were not significantly different $(p=0.63)$ (see Additional file 1 : Table S1), their elevations are significantly different from each other $(p<0.001)$ (Fig. 1).

According to Table 1, the demographic characteristics and birth outcomes of terms and preterms are similar, except for birth weight, which is lower in preterms $(p<0.05)$. Our sample is composed mostly of moderate to late preterms (GA 32 to $<37$ weeks), which represent about $10 \%$ of all births [26]. Their prematurity ranged from 0.15 to 5.72 weeks (average $2.78 \pm 1.58$ weeks).

For the infants evaluated at 1-month, the average latency of the P1 component was not significantly 
Table 1 Demographic characteristics and birth outcomes

\begin{tabular}{|c|c|c|c|c|}
\hline & $\begin{array}{l}\text { Total sample, } N=23 \\
n(\%)\end{array}$ & Preterm, $n=12$ & Term, $n=11$ & $p$ value \\
\hline \multicolumn{5}{|l|}{ Maternal age $\mathrm{a}^{\mathrm{a}}$} \\
\hline$<34$ (y. o.) ${ }^{b}$ & $8(66.67)$ & $2(66.67)$ & $6(66.67)$ & \multirow[t]{2}{*}{$>0.05$} \\
\hline >35 (у. о.) & $4(33.33)$ & $1(33.33)$ & $3(33.33)$ & \\
\hline \multicolumn{5}{|l|}{ Education } \\
\hline Less than middle-school & $17(94.44)$ & $8(100.00)$ & $9(90.00)$ & \multirow[t]{2}{*}{$>0.05$} \\
\hline More than middle-school ${ }^{c}$ & $1(5.56)$ & $0(0.00)$ & $1(10.00)$ & \\
\hline \multicolumn{5}{|l|}{ Sex of child } \\
\hline Male & $10(43.48)$ & $6(46.16)$ & $4(40.00)$ & \multirow[t]{2}{*}{$>0.05$} \\
\hline Female & $13(56.52)$ & $7(53.84)$ & $6(60.00)$ & \\
\hline \multicolumn{5}{|l|}{ Gestational age } \\
\hline 31 to $<37$ weeks & $13(56.52)$ & $13(100.0)$ & $0(0.00)$ & \multirow[t]{2}{*}{$<0.05$} \\
\hline$>37$ weeks & $10(43.48)$ & $0(0.00)$ & $10(100.0)$ & \\
\hline \multicolumn{5}{|l|}{ Birth weight ${ }^{\mathrm{e}}$} \\
\hline$<2500 \mathrm{~g}$ & $10(50.00)$ & $10(83.33)$ & $0(0.00)$ & \multirow[t]{2}{*}{$<0.05$} \\
\hline$>2500 \mathrm{~g}$ & $10(50.00)$ & $2(16.67)$ & $8(100.00)$ & \\
\hline \multicolumn{5}{|c|}{ Family income (in minimum wages) ${ }^{f}$} \\
\hline$<1$ & $8(50.00)$ & $3(42.85)$ & $5(55.55)$ & \multirow[t]{2}{*}{$>0.05$} \\
\hline 1 to 5 & $8(50.00)$ & $4(57.15)$ & $4(44.45)$ & \\
\hline \multicolumn{5}{|l|}{ Socioeconomic status ${ }^{g, h}$} \\
\hline$A, B$, and $C$ & $6(30.00)$ & $1(9.10)$ & $5(55.55)$ & \multirow[t]{2}{*}{$<0.05$} \\
\hline $\mathrm{D}$ and $\mathrm{E}$ & $14(70.00)$ & $10(90.90)$ & $4(44.45)$ & \\
\hline \multicolumn{5}{|l|}{ NICU admission' } \\
\hline No & $6(42.85)$ & $3(50.00)$ & $3(37.50)$ & \multirow[t]{2}{*}{$>0.05$} \\
\hline Yes $^{j}$ & $8(57.15)$ & $3(50.00)$ & $5(62.50)$ & \\
\hline
\end{tabular}

a 11 missing values

${ }^{b}$ y.o.: years old

c 5 missing values

d 31.28 weeks

e 3 missing values

f 8 missing values

93 missing values

${ }^{\mathrm{h}}$ Brazil Economic Classification Criteria (https://www.abep.org/criterio-brasil)

i 9 missing values; ${ }^{\mathrm{j}}$ All infants stayed in NICU for 2 days
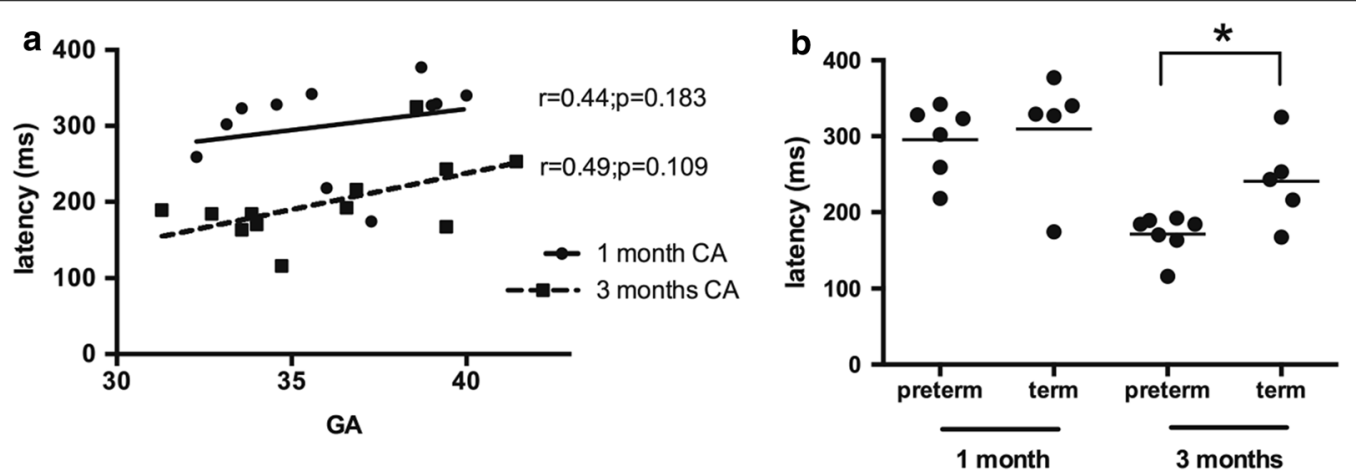

Fig. 1 a P1 latencies recorded at 1- and 3-months CA as a function of GA. Linear regression lines are superimposed on the raw data for the CAEP recordings at 1- or 3-months CA, respectively. $\mathbf{b}$ Latency of the P1 component of the CAEP of preterm (GA<37 weeks) and term (GA $\geq 37$ weeks) infants recorded at 1 - or 3-months CA. Lines represent the median. ${ }^{*} \mathrm{p}<0.05$ 
different between terms $(309.40 \pm 78.32 \mathrm{~ms})$ and preterms $(295.30 \pm 47.66 \mathrm{~ms})(U=10, p=0.4242)$ (Fig. 1b). However, for the group evaluated at 3-months, average P1 latency was $240.80 \pm 57.67 \mathrm{~ms}$ for terms and $171.1 \pm 26.44 \mathrm{~ms}$ for preterms, respectively (Fig. 1b), and significantly lower for the latter $(U=5, p<0.05)$. The grand average CAEP waveforms at 1 - and 3 -months are shown in Fig. 2a, b, respectively. The latency of the P1 component at 3-months is smaller than at 1 -month for the preterm group $(176.00 \pm 29.16 \mathrm{~ms}$
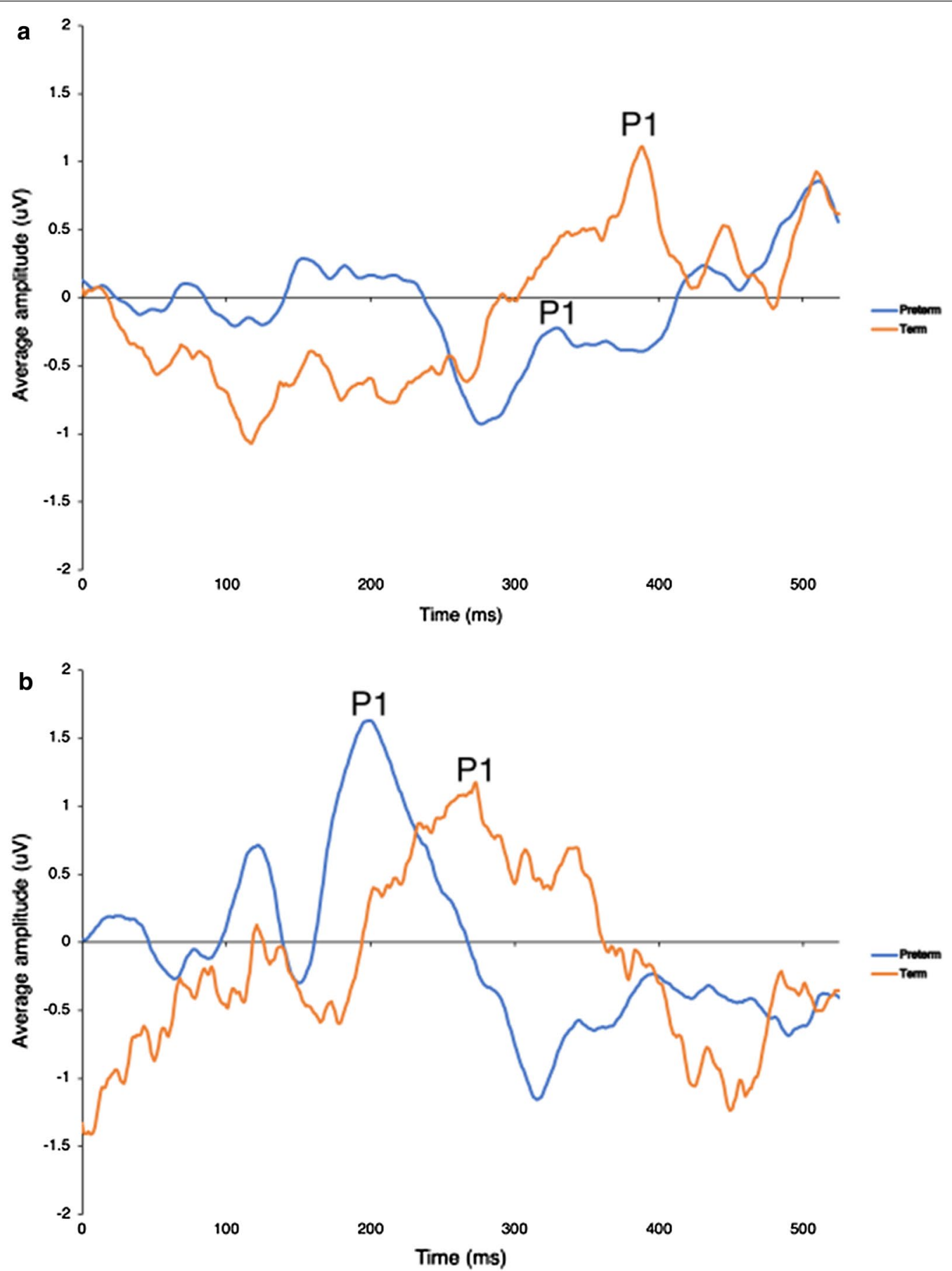

Fig. 2 Grand average waveforms of the CAEP of the term and preterm groups recorded at 1- (a) and 3-months (b) CA. The arrows indicate the P1 component 
vs $295 \pm 47.65 \mathrm{~ms} ; U=1, p=0.005)$, but not the term group $(247.00 \pm 64,64 \mathrm{~ms}$ vs. $309.40 \pm 78.31 \mathrm{~ms} ; U=17$, $p=0.1111)$.

\section{Discussion}

The maturation of cortical circuits is coordinated by genetic and experience-dependent mechanisms [27]. The susceptibility of developing cortical circuits to environmental factors begins in the womb [28] and this is underscored the capacity of human newborns to immediately interact with their caregivers [7, 29, 30].

The last trimester of gestation is marked by rapid cortical growth [31,32]. While the premature exposure to the extrauterine environment during this period may interfere with the maturation of association areas and increase the risk of neurodevelopmental impairment [33], the rate of cortical maturation is not synchronous across cortical regions [4, 34]. In the primary auditory cortex, for instance, developmental changes in cortical microstructure have largely occurred by 28 weeks of gestation [4]. This differential pattern of cortical maturation might explain why non-primary areas are more vulnerable to disruption due to premature exposure to the extrauterine environment $[35,36]$ while primary areas may experience an acceleration in maturation $[9,10]$. According to our findings (see Fig. 1b), the earlier exposure to extrauterine sound stimulation in late-preterm infants probably speeds up the maturation of auditory cortical circuits and improves the efficiency of auditory input processing in this population during the first months of postnatal life [37].

An earlier study [38] had already reported that P1 latency was similar in 1-month-old terms and preterms. However, our study is the first to show that P1 latency in a group of 3 months old infants is shorter in moderateto-late preterms (see Fig. 1b). Previous works had shown that P1 latency steadily decreases from around $250 \mathrm{~ms}$ in 1-month-old infants towards $100 \mathrm{~ms}$ in adults [39, 40]. The smaller P1 latency of preterms in the 3-month CA group probably reflects the accelerating maturational effects of early exposure to the extrauterine environment, which usually includes speech stimulation [41].

Other studies had already investigated the effect of preterm birth on the maturation of auditory cortical pathways in pre-schoolers using P1 as a biomarker [42-45]. However, the preterms in those studies were classified as extreme/very-preterm and the poor results they observed in comparison to controls may have been influenced by concurrent clinical conditions associated with extreme prematurity [45].

The neural mechanisms associated with the accelerating effects of preterm birth on the maturation of cortical pathways remain to be determined. One possibility is an increase in the effectiveness of thalamocortical connectivity with the primary auditory cortex [1] due to precocious exposure to the external social environment. A similar effect was reported previously in the primary somatosensory cortex of very preterm infants $(\mathrm{GA}<33$ weeks) following the premature exposure to activities such as breastfeeding and bottle-feeding [10].

A previous study [46] had shown that the latencies of components $\mathrm{N} 1$ and $\mathrm{P} 2$ are shorter in term than in preterm infants at 3 months of GA. While this result is the opposite we observed in the present work, we suppose this difference stems from the choice of auditory stimuli and the biomarker for physiological maturation. In that study [46], the stimulus was a click while we used speech stimuli (the phoneme/da/). Also, we used the latency of the P1 component as a biomarker, the gold standard for evaluating the maturation of cortical auditory pathways $[17,21,23,47,48]$.

Our results are corroborated by other studies that show the advantages of prematurity in auditory recognition memory [49], binocular vision [9], and language comprehension [50]. Thus, even though preterm birth is associated with many neurodevelopmental risks, especially in small for gestational age (SGA) infants [32], the early exposure to socially relevant stimuli can enhance the maturation of sensory pathways [51]. Though our results differ from studies using visual evoked potentials (VEP) that show that preterm birth negatively affects the development of visual pathways [52, 53], the preterm group in those studies was composed of very preterm infants, which may have been SGA at birth.

\section{Conclusion}

The present results reinforce the notion that early exposure to socially relevant environments contributes to the adaptive maturation of sensory pathways. This understanding is of practical importance since preterm birth is on the rise worldwide. Many preterms need to remain hospitalized in neonatal intensive care units (NICU), isolated from their parents, and subject to continuous loud noises or visual deprivation [54]. These conditions can be further detrimental to the maturation of cortical sensory circuits due to their effect on the levels of stress hormones. Fortunately, the young brain is remarkably resilient and can overcome early insults when provided access to appropriate care, stimulation, and follow-up measures [55].

\section{Limitations}

The main limitations of the present work are (1) the small sample number, (2) the need to use a cross-sectional, instead of a longitudinal experimental design, and (3) the 
fact that we only considered the role of extrinsic variables (environmental exposure), while it is known that cortical maturation is influenced by intrinsic variables as well.

\section{Supplementary information}

Supplementary information accompanies this paper at https://doi. org/10.1186/s13104-020-05129-8.

Additional file 1: Table S1. Correlation and linear regression values for P1 latencies.

\section{Abbreviations}

ABR: Auditory brainstem response; CA: Corrected age; CAEP: Cortical auditory evoked potential; DPOAE: Distortion Product Otoacoustic Emissions; GA: Gestational age; NICU: Neonatal intensive care unit; SGA: Small for gestational age; VEP: Visual evoked potential.

\section{Acknowledgements}

Not applicable.

\section{Authors' contributions}

$\mathrm{SB}$, AP designed the experiments; HGC, ASN, BKC, KA, SB, AP collected data; HGC, ASN, BKC, KA, SB, AP analyzed data; HGC, SB, AP wrote the manuscript. All authors read and approved the final manuscript.

\section{Funding}

Financial support for this work was provided by the Coordination for the Improvement of Higher Education Personnel (CAPES) of the Ministry of Education of Brazil.

\section{Availability of data and materials}

The data that support the findings of this study are available on request from the corresponding author, AP. The data are not publicly available due to ethical restrictions.

\section{Ethics approval and consent to participate}

This study was approved by the Research Ethics Committee of the Federal University of Rio Grande do Norte (\#340.110) and written informed parental consent was obtained on behalf of all participants.

\section{Consent to publish}

All authors consent to the publication of the manuscript in BMC Research Notes.

\section{Competing interests}

The authors declare that the research was conducted in the absence of any commercial or financial relationships that could be construed as a potential competing interests.

\section{Author details \\ ${ }^{1}$ Department of Speech and Language Pathology, Federal University of Par- aíba, Cidade Universitária, S/N - Conj. Pres. Castelo Branco III, João Pessoa, PB 58051-900, Brazil. ² Speech and Language Pathology Graduate Program, Federal University of Rio Grande do Norte, Rua Gen. Gustavo Cordeiro de Farias, S/N, Natal, RN 59012-570, Brazil. ${ }^{3}$ Department of Speech and Language Pathology, University of São Paulo, Alameda Dr. Octávio Pinheiro Brisolla, 9-75, Bauru, SP 17012-901, Brazil. ${ }^{4}$ Department of Speech and Language Pathology, Federal University of Rio Grande do Norte, Rua Gen. Gustavo Cordeiro de Farias, S/N, Natal, RN 59012-570, Brazil. ${ }^{5}$ Department of Electrical and Bio- medical Engineering, Institute of Technology, Federal University of Pará, Rua Augusto Correa, S/N, Belém, PA 66075-110, Brazil.}

Received: 1 February 2020 Accepted: 4 June 2020

Published online: 26 June 2020

\section{References}

1. Barkat TR, Polley DB, Hensch TK. A critical period for auditory thalamocortical connectivity. Nat Neurosci. 2011;14(9):1189-94.

2. de Araújo Costa Folha OA, Bahia CP, de Aguiar GPS, Herculano AM, Coelho NLG, de Sousa MBC, et al. Effect of chronic stress during adolescence in prefrontal cortex structure and function. Behav Brain Res. 2017;326:44-51.

3. Hensch TK. Critical period plasticity in local cortical circuits. Nat Rev Neurosci. 2005:6(11):877-88.

4. Monson BB, Eaton-Rosen Z, Kapur K, Liebenthal E, Brownell A, Smyser $C D$, et al. Differential rates of perinatal maturation of human primary and non-primary auditory cortex. eNeuro. 2018;5(1):ENEURO.0380-17.2017.

5. Birnholz J, Benacerraf B. The development of human fetal hearing. Science. 1983:222(4623):516-8.

6. Rotteveel JJ, de Graaf R, Stegeman DF, Colon EJ, Visco YM. The maturation of the central auditory conduction in preterm infants until three months post term. V. The auditory cortical response (ACR). Hearing Res. 1987:27(1):95-110

7. DeCasper A, Fifer W. Of human bonding: newborns prefer their mothers' voices. Science. 1980;208(4448):1174-6.

8. Hepper PG, Scott D, Shahidullah S. Newborn and fetal response to maternal voice. J Reprod Infant Psychol. 1993;11(3):147-53.

9. Jando G, Miko-Barath E, Marko K, Hollody K, Torok B, Kovacs I. Early-onset binocularity in preterm infants reveals experience-dependent visual development in humans. Proc Natl Acad Sci USA. 2012;109(27):11049-52.

10. Toulmin H, Beckmann CF, O'Muircheartaigh J, Ball G, Nongena P, Makropoulos A, et al. Specialization and integration of functional thalamocortical connectivity in the human infant. Proc Natl Acad Sci USA 2015;112(20):6485-90.

11. Abbott A. Neuroscience: the brain, interrupted. Nature. 2015:518(7537):24-6.

12. Goldenberg RL, Culhane JF, lams JD, Romero R. Epidemiology and causes of preterm birth. The Lancet. 2008;371(9606):75-84.

13. Blencowe H, Cousens S, Chou D, Oestergaard M, Say L, Moller A-B, et al. Born Too Soon: the global epidemiology of 15 million preterm births. Reprod Health. 2013;10(Suppl 1):S2.

14. Blencowe H, Cousens S, Oestergaard MZ, Chou D, Moller A-B, Narwal R, et al. National, regional, and worldwide estimates of preterm birth rates in the year 2010 with time trends since 1990 for selected countries: a systematic analysis and implications. Lancet. 2012;379(9832):2162-72.

15. Loftin RW, Habli M, Snyder CC, Cormier CM, Lewis DF, Defranco EA. Late preterm birth. Rev Obstet Gynecol. 2010:3(1):10-9.

16. Adams-Chapman I. Neurodevelopmental outcome of the late preterm infant. Clin Perinatol. 2006;33(4):947-64.

17. Cunningham J, Nicol T, Zecker S, Kraus N. Speech-evoked neurophysiologic responses in children with learning problems: development and behavioral correlates of perception. Ear Hear. 2000;21(6):554-68.

18. de Melo Â, Biaggio EPV, Rechia IC, Sleifer P. Potenciais evocados auditivos corticais em neonatos nascidos a termo e pré-termo. CoDAS. 2016;28(5):491-6.

19. Moore DR. Auditory development and the role of experience. Br Med Bull. 2002;63(1):171-81.

20. Shafer VL, Yu YH, Datta H. The development of English vowel perception in monolingual and bilingual infants: neurophysiological correlates. J Phon. 2011;39(4):527-45.

21. Shafer $V L, Y u Y H$, Wagner M. Maturation of cortical auditory evoked potentials (Caeps) to speech recorded from frontocentral and temporal sites: three months to eight years of age. Int J Psychophysiol. 2015;95(2):77-93.

22. Sharma A, Gilley PM, Dorman MF, Baldwin R. Deprivation-induced cortical reorganization in children with cochlear implants. Int J Audiol. 2007:46(9):494-9.

23. Sharma A, Martin K, Roland P, Bauer P, Sweeney MH, Gilley P, et al. P1 latency as a biomarker for central auditory development in children with hearing impairment. J Am Acad Audiol. 2005;16(8):564-73.

24. Brazelton TB, Nugent JK. Neonatal behavioral assessment scale (Clinics in developmental medicine). Mac Keith Press.; 2011. http://search.ebsco host.com/login.aspx?direct=true\&scope $=$ site $\& d b=$ lebk\&db=nlabk $\& A N=503755$. Accessed May 282020.

25. Banhara MR. Potenciais auditivos de longa latência: N1, P2, N2, P300, evocados por estímulo de fala em usuários de implante coclear [Mestrado 
em Fisiopatologia Experimental]. [São Paulo]: Universidade de São Paulo; 2007. http://www.teses.usp.br/teses/disponiveis/5/5160/tde-17102014111320/. Accessed May 282020

26. United States Department of Health and Human Services (US DHHS), Centers for Disease Control and Prevention (CDC), National Center for Health Statistics (NCHS). Natality public-use data on CDC WONDER Online Database, for years 2016-2018 (Expanded). CDC Wonder. United States Department of Health and Human Services (US DHHS); 2019. https ://wonder.cdc.gov/natality-expanded-current.html. Accessed May 27 2020

27. Nithianantharajah J, Hannan AJ. Enriched environments, experiencedependent plasticity and disorders of the nervous system. Nat Rev Neurosci. 2006;7(9):697-709.

28. Sanes DH, Bao S. Tuning up the developing auditory CNS. Curr Op Neurobiol. 2009;19(2):188-99.

29. Partanen E, Kujala T, Naatanen R, Liitola A, Sambeth A, Huotilainen M. Learning-induced neural plasticity of speech processing before birth. Proc Natl Acad Sci USA. 2013;110(37):15145-50.

30. Webb AR, Heller HT, Benson CB, Lahav A. Mother's voice and heartbeat sounds elicit auditory plasticity in the human brain before full gestation. Proc Natl Acad Sci USA. 2015;112(10):3152-7.

31. Kostović I, Jovanov-Milošević N. The development of cerebral connections during the first 20-45 weeks' gestation. Sem Fetal Neonat Med. 2006;11(6):415-22.

32. Malik S, Vinukonda G, Vose LR, Diamond D, Bhimavarapu BBR, Hu F, et al. Neurogenesis continues in the third trimester of pregnancy and is suppressed by premature birth. J Neurosci. 2013;33(2):411-23.

33. Katz J, Lee ACC, Kozuki N, Black RE. Mortality risk among term and preterm small for gestational age infants. In: Embleton ND, Katz J, Ziegler EE, editors. Nestlé Nutrition Institute Workshop Series. S. Karger AG; 2015. p. 29-35. https://www.karger.com/Article/FullText/365800. Accessed May 282020.

34. Ball G, Srinivasan L, Aljabar P, Counsell SJ, Durighel G, Hajnal JV, et al. Development of cortical microstructure in the preterm human brain. Proc Natl Acad Sci USA. 2013;1 10(23):9541-6.

35. Polin RA, FoxWW, Abman SH. Fetal and neonatal physiology: expert consult (2-volume set). London: Elsevier Health Sciences; 2011.

36. Zhang Y, Inder TE, Neil JJ, Dierker DL, Alexopoulos D, Anderson PJ, et al. Cortical structural abnormalities in very preterm children at 7 years of age. Neurolmage. 2015;109:469-79.

37. Lebenberg J, Mangin J-F, Thirion B, Poupon C, Hertz-Pannier L, Leroy $F$, et al. Mapping the asynchrony of cortical maturation in the infant brain: a MRI multi-parametric clustering approach. Neurolmage. 2019;185:641-53.

38. Didoné $\mathrm{D}$, Garcia M, da Silveira A. Long latency auditory evoked potential in term and premature infants. Int Arch Otorhinolaryngol. 2013;18(01):016-20.

39. Moore JK, Linthicum FH. The human auditory system: a timeline of development. Int J Audiol. 2007:46(9):460-78.

40. Sharma A, Dorman MF, Spahr AJ. A sensitive period for the development of the central auditory system in children with cochlear implants: implications for age of implantation. Ear Hearing. 2002;23(6):532-9.
41. Vouloumanos A, Werker JF. Listening to language at birth: evidence for a bias for speech in neonates. Dev Sci. 2007;10(2):159-64.

42. Green M, Solnit AJ. Reactions to the threatened loss of a child: a vulnerable child syndrome. Pediatric management of the dying child, part III. Pediatrics. 1964;34:58-66.

43. Hövel H, Partanen E, Huotilainen M, Lindgren M, Rosén I, Fellman V. Auditory event-related potentials at preschool age in children born very preterm. Clin Neurophysiol. 2014;125(3):449-56.

44. Hövel H, Partanen E, Tideman E, Stjernqvist K, Hellström-Westas L, Huotilainen $\mathrm{M}$, et al. Auditory event-related potentials are related to cognition at preschool age after very preterm birth. Pediatr Res. 2015;77(4):570-8.

45. Suppiej A, Cainelli E, Cappellari A, Ermani M, Sartori S, Bisiacchi PS. Neonatal cortical auditory evoked potentials are affected by clinical conditions occurring in early prematurity: J Clin Neurophysiol. 2015;32(5):419-23.

46. Pasman JW, Rotteveel JJ, de Graaf R, Stegeman DF, Visco YM. The effect of preterm birth on brainstem, middle latency and cortical auditory evoked responses (BMC AERs). Early Hum Dev. 1992;31 (2):113-29.

47. Ceponiene R, Rinne T, Näätänen R. Maturation of cortical sound processing as indexed by event-related potentials. Clin Neurophysiol. 2002;113(6):870-82.

48. Wunderlich JL, Cone-Wesson BK. Maturation of CAEP in infants and children: a review. Hearing Res. 2006;212(1-2):212-23.

49. deRegnier R-A, Wewerka S, Georgieff MK, Mattia F, Nelson CA. Influences of postconceptional age and postnatal experience on the development of auditory recognition memory in the newborn infant. Dev Psychobiol. 2002;41(3):216-25.

50. Gonzalez-Gomez N, Nazzi T. Phonotactic acquisition in healthy preterm infants: phonotactic acquisition in preterm infants. Dev Sci. 2012;15(6):885-94.

51. Fenoglio A, Georgieff MK, Elison JT. Social brain circuitry and social cognition in infants born preterm. J Neurodev Disord. 2017:9(1):27.

52. Sayeur MS, Vannasing P, Tremblay E, Lepore F, McKerral M, Lassonde M, et al. Visual development and neuropsychological profile in preterm children from 6 months to school age. J Child Neurol. 2015;30(9):1159-73.

53. Tremblay E, Vannasing P, Roy M-S, Lefebvre F, Kombate D, Lassonde M, et al. Delayed early primary visual pathway development in premature infants: high density electrophysiological evidence. PLOS ONE. 2014;9(9):e107992.

54. Wachman EM, Lahav A. The effects of noise on preterm infants in the NICU. Archiv Dis Childhood Fetal Neonatal Ed. 2011;96(4):F305-9.

55. Caldas IFR, Garotti MF, Shiramizu VKM, Pereira A. The socio-communicative development of preterm infants is resistant to the negative effects of parity on maternal responsiveness. Front Psychol. 2018;2(9):43.

\section{Publisher's Note}

Springer Nature remains neutral with regard to jurisdictional claims in published maps and institutional affiliations.

Ready to submit your research? Choose BMC and benefit from

- fast, convenient online submission

- thorough peer review by experienced researchers in your field

- rapid publication on acceptance

- support for research data, including large and complex data types

- gold Open Access which fosters wider collaboration and increased citations

- maximum visibility for your research: over 100M website views per year

At BMC, research is always in progress.

Learn more biomedcentral.com/submissions 